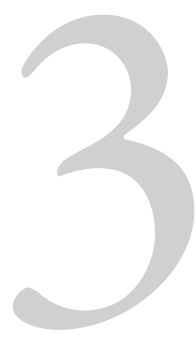

\title{
LOS FONDOS CON ASIGNACIÓN ESPECÍFICA. INCIDENCIA EN LOS MUNICIPIOS DE LA PROVINCIA DE BUENOS AIRES, ARGENTINA
}

\author{
SPECIAL PURPOSE FUNDS. THEIR \\ IMPACT ON THE MUNICIPALITIES \\ OF THE PROVINCE OF BUENOS \\ AIRES, ARGENTINA
}

\section{Ricardo Sebastián Piana}

Recibido: $12 / 02 / 2020$

Aceptado: $16 / 04 / 2020$

\section{RE S U M E N}

Aun cuando la autonomía jurídica sigue siendo una asignatura pendiente en el sistema político de la Provincia de Buenos Aires, Argentina, los aspectos económicos también pueden condicionarla fuertemente. En este trabajo abordaremos las limitaciones económicas a la autonomía de los municipios a través de la creciente transferencia de fondos por parte de la Provincia con asignación específica. Identificaremos el complejo entramado de normas provinciales que limitan sus competencias económicas y consecuentemente, capacidades de decisión. Ya sea porque obligan o condicionan el direccionamiento de los fondos, este tipo de normas afectan las competencias, las políticas públicas locales y capacidades de las autoridades municipales. Concluimos que los criterios de reparto evidencian grandes diferencias y afectan fuertemente a los municipios pequeños con baja capacidad recaudatoria.

\section{PA L A B A S C L AVES}

federalismo fiscal - finanzas municipales - fondos con asignación específica - presupuesto público - Provincia de Buenos Aires.

1. Universidad Nacional de La Plata, La Plata y Universidad del Salvador, Buenos Aires, Argentina.

Contacto: rspiana@gmail.com 


\section{A B S T R A C T}

Although legal autonomy remains a pending issue in the political system of the Province of Buenos Aires, Argentina, economic aspects can also strongly condition it. In this work we will address the economic limitations to the autonomy of the municipalities through the increasing quantity of funds that the Province gives with specific assignation in theirs Budgets. We will identify the complex network of provincial norms that limit their economic competences and, consequently, decision-making capabilities. Either because they force or condition the direction of the funds, these types of regulations affect the powers, local public policies and capacities of municipal authorities. We conclude that the distribution criteria show great differences and strongly affect small municipalities with low collection capacity.

\section{K E Y W O R D S}

fiscal federalism - funds with specific destination - municipal finance - public budget - Province of Buenos Aires.

\section{I N T R O D U C C I Ó N}

Una nota del federalismo fiscal argentino es que los recursos se ingresan, en su mayoría, para o desde las organizaciones públicas superiores mientras que existe, por regla, más descentralización en materia de gastos. Este sobra-falta de recursos se "corrige" con la transferencia de fondos desde el gobierno superior a los inferiores, esto es, del Estado nacional a provincias y de provincias a municipios ${ }^{2}$. Ahora bien, esas transferencias verticales pueden ser de libre disponibilidad o encontrarse afectadas.

El principio presupuestario de no afectación propugna que todos los ingresos de los entes públicos se destinen a satisfacer, de modo genérico e indistinto, todos los gastos públicos (Nava Escudero, 2014³). Se desaconseja, por

2. En efecto, los tres niveles de gobierno del Estado argentino no son iguales, no solo en cuanto a competencias, sino especialmente en cuanto a sus capacidades económicas, lo que da cuenta del desequilibrio de su federalismo fiscal. Es expresión de la asimetría en la capacidad económica de la Nación, las Provincias y los municipios la desigual capacidad de recaudación y gasto. La consecuencia es advertida por López Accoto, Martínez, Grinberg y Mangas (2013:16): "Un gasto crecientemente local y una recaudación cada vez más centralizada - afirman - tienen el efecto de incrementar la importancia y necesidad de sistemas de transferencias financieras entre niveles de gobierno de modo tal de reducir el desbalance entre responsabilidades de gasto y potestades sobre las fuentes de recursos públicos (...)".

3.En el ámbito normativo nacional, la Ley N²4.156 de Administración Financiera y de los Sistemas de Control, en su art. 23 señala "No se podrá destinar el producto de ningún rubro de ingresos con el fin de atender específicamente el pago de determinados gastos, con excepción de: a) Los provenientes de operaciones de crédito público; b) Los provenientes de donaciones, herencias o legados a favor del Estado nacional, con destino específico; c) Los que por leyes especiales tengan afectación específica". La Provincia, en su ley específica, replica este artículo (ver art. 22 Ley $N^{\circ}$ 13.767). 
lo tanto, que algunos ingresos o un porcentaje de ellos se destinen a satisfacer ciertos gastos concretos ${ }^{4}$. Se señala que este principio resguarda que el Estado sea, en cualquiera de sus niveles, políticamente responsable de fijar el orden de prioridad de las necesidades y los gastos destinados a atenderlas; a contrario, si otro fuera quien fija en qué pueden invertirse los fondos y cuánto puede gastarse, este otro sujeto es quien efectivamente gobierna. Cuando existe un fondo con afectación específica, ese gasto ha de cumplirse en su integralidad; el fondo es un piso y no un techo por lo que si los fondos no son suficientes, los gastos deben cubrirse con las rentas generales; a la inversa, si hay superávit, no se autoriza su reasignación. Es entonces el principio presupuestario de no afectación una clave para entender el grado y naturaleza de la autonomía de un gobierno.

En el contexto de la reforma constitucional del año ‘94, un nuevo abanico de posibilidades se abrió para los municipios. Sin embargo, el proceso de autonomía política ha demostrado ser ilusorio sin la debida autonomía en sus recursos económico financieros ya que, como veremos, sus capacidades dependen, en gran medida, de sus ingresos ${ }^{5}$.

Existen diversos estudios sobre los aspectos económicos de los municipios. En el clásico artículo de Oscar Cetrángolo y Juan Pablo Jiménez (2004) se tratan las relaciones fiscales y financieras entre el gobierno nacional y los gobiernos provinciales en Argentina desde los ‘90, incluyendo en su análisis a los municipios. El artículo de López Accotto, Grinberg y Martínez (2010) estudia las transferencias intergubernamentales de la provincia a sus municipios, especialmente la coparticipación; realiza un análisis histórico-normativo, la evolución de los criterios de distribución y se compara, vía análisis estadístico, los patrones territoriales de los distintos esquemas de reparto. La tesis de Catalano (2010) también trabaja el régimen de coparticipación entre la Provincia de Buenos Aires y sus municipios. Una investigación sobre la estructura de la recaudación municipal en la Argentina, elaborado por la Universidad Nacional de General Sarmiento y la Secretaría de Asuntos Municipales (2015) estudia el marco fiscal de los municipios y los recursos propios municipales proponiendo buenas prácticas de gestión y recomendaciones.

López Accotto, Martínez, Grinberg y Mangas (2013) presenta una importante investigación que estudia la fiscalidad sub-nacional en la Provin-

4. Todo ingreso deberia ir, entonces, a la misma cuenta, la de rentas generales, y poder ser utilizado para cubrir los gastos que las autoridades decidan priorizar.

5. omo se ha sido dicho "(...) la ausencia de autonomía financiera repercute sobre la efectiva vigencia de la autonomía en sus demás aspectos; así, la autonomía institucional, política y administrativa se vería afectada tanto por la falta de recursos como por la imprevisibilidad en cuanto a los montos a percibir" (Flores et. al., 2016:7). 
cia de Buenos Aires y sus municipios como un todo, estudiando tanto los fondos coparticipables como las transferencias fuera de este mecanismo y proponiendo nuevos esquemas de distribución. Alguno de estos autores, Mangas, López Accotto y Martínez (2016) dan continuidad a ese estudio y analizan la evolución de una serie de variables relevantes para el análisis del desempeño fiscal de los gobiernos de nivel municipal (composición de los ingresos y gastos municipales, la autonomía financiera, el resultado financiero, el autofinanciamiento y la inversión pública local) ${ }^{6}$.

Flores, Gil, Iparraguirre y Altavilla (2016), en el marco de un proyecto de investigación de la Universidad Nacional de San Luis (UNSL) publican un interesante paper sobre el rol de los municipios en el desarrollo local en el contexto de las dificultades en la generación de los propios recursos y su dependencia a los recursos provinciales. Se demuestra que para 2009, del total de gastos, el 30,88\% se destina al funcionamiento del Estado municipal; el $61,43 \%$ en gasto público social; un $7,18 \%$ en servicios económicos y un $0,51 \%$ en servicios de la deuda pública. Estos datos dan cuenta de una reorientación, a través de sus gastos, de los fines del gobierno local. También, a través de encuestas, se pregunta a intendentes qué tipo de gastos preferirían realizar destacándose cómo la preferencia se concentra sobre el gasto en Promoción y Asistencia Social, dato central para este estudio.

Gola y Schiavi (2017) también estudian la coparticipación provincial bonaerense aportando relevantes indicadores. Un informe del año 2017 del Centro de Implementación de Políticas Públicas para la Equidad y el Crecimiento (CIPPEC) indaga la relación fiscal entre el gobierno nacional y las provincias ${ }^{7}$. Por último, se ha detectado un interesante informe del Ob-

6. Los 277 casos que comprende el estudio de gobiernos locales cubre el $66 \%$ de la población argentina. Como resultado de ese estudio se informa que el gasto consolidado municipal representa el 3,7\% del PBI, mientas que los ingresos apenas alcanzan el 1,3\% del PBl; entre un 60\% y $80 \%$ de la recaudación propia de los municipios proviene de las tasas, derechos y contribuciones; desde 1993 a 2013 la participación de los municipios en el gasto público se ha mantenido constante, pero en materia de ingresos existió una merma considerable, por lo que en el contexto de las mayores actividades y funciones que tienen, la dependencia de los municipios a las transferencias de Nación y Provincia ha aumentado en forma sensible; la presión fiscal de Nación creció de 17,9\% a 32,1\% entre 1993 y 2013, mientras que en las provincias creció de 3,7\% a 6,5\% y la de los municipios sólo pasó de 1,2 a 1,4\% en igual período; los recursos propios corrientes de los municipios estudiados llegan al 42\%, lo que comprende un $35 \%$ proveniente de tasas, derechos y contribuciones y un 7\% de otro tipo de recursos propios corrientes, como los impuestos, regalias y otros (Mangas, López Accotto y Martínez, 2016).

7. "En el caso de nuestro país, y tomando como referencia el año 2015, (...) el Gobierno Nacional recauda el 76,5\% del total de los recursos totales y ejecuta el $57,8 \%$ del gasto, mientras que las provincias y municipios cobran tributos que representan el $23,5 \%$ de los recursos y realizan el $42,2 \%$ de las erogaciones. Esto deviene en que la mayoría de las provincias financian más de la mitad de sus gastos con transferencias del gobierno nacional, alcanzando dicha proporción el 90\% en casos extremos" (Agosto, 2017:2). 
servatorio del Estado Provincial (2018) que detalla las transferencias del gobierno nacional a los municipios ${ }^{8}$.

Por el lado de la información pública de acceso abierto, la Provincia de Buenos Aires cuenta con un sistema de consultas web con infografías que dan cuenta de qué porcentaje de los fondos de los municipios provienen de recursos propios, tienen origen provincial, nacional o derivan de otras fuentes ${ }^{9}$.

A pesar de este nutrido desarrollo del estado del arte y la información pública que actualmente está disponible, no hemos detectado ningún estudio ni información que ponga su acento en los fondos provinciales que se transfieren a los municipios con afectación específica, su incidencia en el presupuesto y su vinculación con la autonomía municipal.

Investigaremos los alcances de la autonomía de los municipios de la Provincia de Buenos Aires en el plano económico utilizando como indicador negativo los fondos con afectación específica y su incidencia. Identificaremos cómo inciden ese tipo de fondos en los municipios de Adolfo Gonzales Chaves, Pilar, General San Martín, San Antonio de Areco y Tigre ${ }^{10}$.

Veremos cómo organizaciones locales de gran tamaño y complejidad, cómo los municipios de la Provincia de Buenos Aires, encuentran restricciones multicausales en lo económico que menguan sus distintas autonomías y que pueden afectar su modalidad de gestión.

Concluiremos que con la asignación de estos fondos se limita la capacidad local de los gobiernos de definir sus políticas, especialmente a los más pequeños, con menos capacidad recaudación propia ${ }^{11}$.

8. "Los municipios de la provincia de Buenos Aires se financian con recursos propios y recursos de origen nacional y provincial, el promedio de los 135 municipios para el 2016 fue del 34\% para los recursos propios, 60\% para las transferencias de provincia y 6 \% para las transferencias de Nación" (Observatorio del Estado Provincial, 2018:1).

9. http://www.buenosairesabierta.org/municipios

10. No trabajamos en esta investigación la gran desigualdad que existe entre los municipios bonaerenses entre sí, en general, ni los del Conurbano con la Ciudad Autónoma de Buenos Aires en particular. Si bien la C.A.B.A. es una jurisdicción que se encuentra en un nivel distinto a los municipios de las provincias, tiene funciones comparables con ellos. La "General Paz" divide mucho más que una Jurisdicción: "Cuentas Metropolitanas que son muy desiguales, como la propia área metropolitana de Buenos Aires; en donde el presupuesto de la Ciudad de Buenos Aires (CABA) dobla los presupuestos de los 24 distritos del conurbano (GBA) sumados, desigualdad que se profundiza si se tiene en cuenta que el GBA tiene una población que cuatriplica la de CABA, y una tasa de pobreza sustancialmente más alta. Según el último informe del INDEC, del segundo semestre de 2016, en CABA hay 277.000 pobres mientras que el GBA supera los 4 millones" (Gola y Schiavi, 2017:2).

11. No es el objetivo de este trabajo analizar los criterios de reparto más o menos objetivos que existen en las leyes provinciales de carácter impositivo, que merecería un más profundo, comparado y detallado análisis. Los criterios para el reparto pueden ser muchos, tales como la brecha de desarrollo; población, densidad, necesidades insatisfechas, etc. Lo que es imprescindible destacar es que siempre cuáles criterios y con qué porcentajes se reparte es un criterio político y no técnico. 


\section{EL S I S T EMA DE C OPART I C I PAC I ÓN B O NA E R E N S E}

Cada provincia es la que regula la autonomía económico financiera en el marco y con los límites que le fija el art. 123 de la Constitución Nacional ${ }^{12}$, ya sea reconociendo los pisos y bases para la imposición tributaria municipal, mediante la transferencia de recursos garantizados o bien mediante una combinación de ambas. No hay, en consecuencia, un único sistema pero implica, al menos, la capacidad de organizar sus rentas o ingresos, administrar su presupuesto y recursos y decidir su inversión sin contralor o dependencia de otro poder ${ }^{13}$.

Los municipios de la Provincia de Buenos Aires obtienen sus recursos de distintas fuentes: como entes autónomos pueden constitucionalmente fijar y recaudar sus propios tributos; si bien encuentran muchas limitaciones normativas, es la expresión propia y concreta de la autonomía municipal en su faz económica y financiera ${ }^{14}$. Sin embargo, “(...) los municipios del Conurbano solamente cuentan, como principal recurso propio, con las tasas que pueden cobrar, a las personas propietarias de inmuebles, a cambio de los servicios de alumbrado, barrido y limpieza $(A B L)$, y a las empresas, por el servicio de inspección de seguridad e higiene (SeH)". (Martínez, 2018:2) $)^{15}$. Las tasas, derechos y contribuciones generan los mayores ingresos pero, como ya indicamos, no son suficientes para su sustentabilidad ya que no llegan ni a cubrir el 50\% de sus gastos.

Otra fuente posible de los recursos proviene de la Nación: no suele ser un

12. El texto reza: "Artículo 123.- Cada provincia dicta su propia constitución, conforme a lo dispuesto por el Artículo $5^{\circ}$ asegurando la autonomía municipal y reglando su alcance y contenido en el orden institucional, político, administrativo, económico y financiero".

13. Se ha dicho que con la autonomía económica se "(...) está reconociendo a ese gobierno local la potestad para desarrollar políticas públicas en ese preciso ámbito cuya finalidad es el desenvolvimiento comunal a través de planes y estrategias que, sin divorciarse de la economía nacional y provincial, alienten emprendimientos, consoliden servicios, promuevan actividades y otros rubros orientados al progreso de las ciudades y al mejoramiento de las condiciones de vida de la sociedad que integran la territorialidad gobernada" (Losa y Cohn, 1998: 42).

14. Si bien hay alguna discusión respecto a esta capacidad impositiva, entendemos con Garcia Belsunce (1982), Baistrocchi (1996), Álvarez Echagüe (2005), Muñoz (2019) entre otros, que los municipios sí tienen capacidad para crear impuestos. Solo que, en función de las limitaciones nacidas de leyes y convenios suscriptos por Nación y Provincia, esta capacidad es muy limitada. En el caso bonaerense, no solo la Ley Orgánica de Municipalidades les reconoce esta facultad en su artículo 29 (aunque el 227 señala que es una denominación genérica) sino también la propia constitución local admite en el capítulo que trata el régimen municipal la posibilidad de los Concejos Deliberantes de fijar impuestos.

15. Y con acierto señala que dado los escasos fondos propios de los municipios, los recursos originados en estas tasas deben ser redestinadas no solo a cubrir esos gastos sino que se redistribuyen a solventar la multiplicidad de tareas que hoy llevan a cabo. Por nuestra parte, agregamos que esta necesidad de generar nuevos ingresos hace que mucho de ellos "caigan" en la trampa de crear tasas con carácter impositivo (sin contraprestación). Bennardis (1999: 11) también señalaba que "cuando se compara la recaudación de la tasa con el costo del servicio, se deduce que esta incluye un impuesto implícito o encubierto". 
ingreso relevante, pero es importante identificarlos por cuanto su transferencia, mayoritariamente, es discrecional ${ }^{16}$.

Por último, los recursos pueden ser de origen provincial y éstos ser de libre disponibilidad o encontrarse afectados. Como ya señalamos, en el ámbito bonaerense, los ingresos más importantes para los municipios provienen de la Provincia y éstos llegan a través de distintos esquemas de reparto.

El porcentaje más grande de los recursos que llegan de la Provincia de Buenos Aires a sus municipios son mediante la coparticipación directa y automática $^{17}$. La norma vigente que regula el sistema de redistribución impositiva es la Ley $\mathrm{N}^{\circ} 10.559^{18}$ de 1987 , aunque ha sido varias veces modificada. Dicha ley fija la coparticipación del 16,14\% de ingresos provinciales percibidos en concepto de impuestos sobre los Ingresos Brutos no descentralizados al ámbito municipal, Impuesto Inmobiliario Urbano, Impuesto a los Automotores, Impuesto de Sellos, Tasas Retributivas de Servicios y Coparticipación Federal de Impuestos en base a los siguientes criterios de distribución e indicadores ${ }^{19}$ :

a) El 58\% entre todas las municipalidades de acuerdo a lo siguiente:

1. $62 \%$ en proporción directa a la población

2. $23 \%$ en forma proporcional a la inversa de la capacidad tributaria per capita, ponderada por la población.

3. $15 \%$ en proporción directa a la superficie del Partido

16. Normalmente no sobrepasa un dígito porcentual del total de ingresos. Sin embargo, estas transferencias discrecionales o planes de obras directamente ejecutadas por la Nación en asuntos estrictamente locales pueden ser muy importantes. Por ejemplo, según el informe del Centro de Estudios Metropolitanos, en 2017, las transferencias y obras de Nación sobre el municipio de Quilmes duplicaron su propio presupuesto (conf. Gola y Schiavi, 2017).

17. La coparticipación de impuestos deviene en un sistema de coordinación financiera necesario cuando, en un sistema federal como el nuestro, existen varias jurisdicciones (niveles) con potestades tributarias propias. Pero además, "(...) en los paises federales que no existe correspondencia entre las necesidades de gasto de los niveles de gobierno y sus posibilidades de recaudar, (...) debe recurrirse a algún sistema de transferencias verticales tendiente a compensar esta diferencia. Que permiten también compensar diferencias horizontales, surgidas por la existencia de regiones más ricas que otras" (Catalano, 2010:8). Es decir, la coparticipación no solo permite ordenar sino también mejor distribuir los ingresos en función de las necesidades.

18. http://www.gob.gba.gov.ar/legislacion/legislacion/l-10559.html Como veremos más adelante, parte de este articulado ha sido modificado por la Ley $N^{\circ}$ 13.010. La Ley N 14.890, que crea un régimen para la regularización de las obligaciones adeudadas por los agentes de recaudación de los Impuestos sobre los Ingresos Brutos y de Sellos o sus responsables solidarios, crea un fondo que se distribuye a municipios en concepto de coparticipación del $16,14 \%$ y según lo dispuesto en la Ley № 10.559 . Además, el veinte por ciento (20\%) del total producido por el régimen establecido en los artículos $1^{\circ}$ y $2^{\circ}$ será girado directamente a los municipios de manera automática y diaria y será distribuido entre éstos de acuerdo al Índice de Vulnerabilidad Social dispuesto por el artículo $6^{\circ}$ inc. a) de la Ley N¹3.163 y modificatorias. Son fondos, de todas formas, de libre disponibilidad. En: http://www.gob.gba. gov.ar/legislacion/legislacion/l-14890.html

19.También hay una referencia a la coparticipación en la explotación de casinos que le corresponda a la Provincia por aplicación de los convenios vigentes entre ésta y la Lotería Nacional. 
b) El $37 \%$ entre las municipalidades que posean establecimientos oficiales para la atención de la salud -con o sin internación-,

c) El 5\% entre las municipalidades que cubrieran servicios o funciones que cubría la provincia pero que por ser netamente municipales fueron transferidas por aplicación del Decreto-Ley $N^{\circ} 9.347 / 79$ y sus modificatorias ${ }^{20}$, excepto del sector Salud Pública, en función de la participación relativa que cada Comuna tuvo en el Ejercicio del año 1986.

El Coeficiente Único de Distribución (CUD) así creado determina un criterio fijo y en base a datos objetivos (no discrecional), tales como población, superficie y tipo de servicios. Sin embargo, el CUD ha sido muy criticado por favorecer a los municipios del interior porque, medido por personas, los municipios del conurbano son los más desfavorecidos ${ }^{21}$; por los del interior, porque los parámetros redistributivos sobrevaloran población respecto de superficie, ya que respecto del 100\% coparticipable, el 35,96\% se corresponde con población y menos del $10 \%(8,7 \%)$ a territorio ${ }^{22}$. Se dice que la coparticipación por servicios de salud benefician a municipios que ya tienen estos servicios pero no a quienes deben hacer la inversión inicial (Gola y Schiavi, 2017) y no atiende a otros criterios de mayor justicia social, como la cantidad de personas sin seguro de salud (López Accotto, Martínez, Grinberg y Mangas, 2013). Se lo critica, por último, por no premiar a aquellos que más recaudan ya que el 13,34\% del total (o el 23\% del 58\%) es en forma proporcional a la inversa de la capacidad tributaria ${ }^{23}$. Por ello, recurrentemente sobrevuela la idea su modificación ${ }^{24}$.

En este sistema de coparticipación es el Ministerio de Economía de la Provincia de Buenos Aires, como autoridad de aplicación, quien tiene la res-

20. http://www.gob.gba.gov.ar/legislacion/legislacion/l-9347.html

21. Como señalan López Accotto, Grinberg y Martínez (2010:87-88) "Un primer hecho notable (...) es que los Municipios Rurales han recibido del gobierno provincial, en promedio para el periodo bajo estudio [2003-2008], una coparticipación por habitante que prácticamente triplica la que recibe el Conurbano Bonaerense y duplica el promedio provincial. Mientras que las Ciudades del Interior reciben una coparticipación por habitante un 8\% superior a la que perciben sus pares del Conurbano".

22. Según el informe del Centro de Estudios Metropolitanos, en la distribución de fondos provinciales "(...) el 47\% lo recibieron los 24 distritos del conurbano, donde habitan el 64\% de los bonaerenses" (Gola y Schiavi, 2017:5), pero que comprende territorialmente solo el 1,18\% respecto de la superficie total de la Provincia.

23. Para un estudio pormenorizado, ver López Accotto, Martínez, Grinberg y Mangas (2013).

24.https://www.eldia.com/nota/2018-3-9-3-22-42-la-provincia-modificara-el-sistema-de-coparticipa-

cion-a-los-municipios-politica-y-economia

25. "El complejo entramado institucional por el que circula toda la información que permite la elaboración del coeficiente no tiene como contrapartida un sistema de fiscalización y control de los datos por parte de una instancia institucional superior, como la Legislatura provincial o el Tribunal de Cuentas de la provincia. La Legislatura solamente se ocupa de verificar y fiscalizar en la presentación del presupuesto provincial los cálculos vinculados a la distribución primaria. Es decir, controla que se prevea la transferencia del 16,14\% de la masa coparticipable provincial a los municipios, en función de lo determinado por la ley, pero no hace ningún control sobre la distribución secundaria." López Accotto, Martínez, Grinberg y Mangas (2013:58). 
ponsabilidad de la distribución y cálculos de la coparticipación ${ }^{25}$. No existe organismo multilateral, tal como la Comisión Federal de Impuestos a nivel Nación-Provincias, lo cual es otro dato relevante acerca de la limitación de la autonomía municipal ${ }^{26}$.

Existe también para los municipios la posibilidad de obtener fondos de origen provincial mediante la descentralización administrativa tributaria autorizada por el artículo 10 del Código Fiscal de la Provincia de Buenos Aires (Ley No 10.397 y modif.) previa suscripción de convenios con el Ministerio de Economía de la Provincia de Buenos Aires, percibiendo éstos un porcentaje de la distribución sobre la recaudación obtenida. En este caso, los montos son de libre disponibilidad ${ }^{27}$.

Según informaba la Mesa de Responsables de Asuntos Municipales, integrada por representantes de diferentes Provincias de la República Argentina y la Dirección Nacional de Coordinación Fiscal con las Provincias (DNCFP), para 2013 "Más del 80\% de dichos recursos se transfieren de manera diaria y automática a todos los Municipios" (Argentina, 2014:3), es decir, mediante un sistema de coparticipación. Pero ese número, en la Provincia de Buenos Aires, representa poco más del 75\% como puede verse en el siguiente gráfico y el resto, son fondos específicos con diferentes tipos de transferencia.

Como se desprende del gráfico 1, el mayor volumen de los fondos llega a los municipios a través de la coparticipación. Pero han señalado López Accotto, Martínez, Grinberg y Mangas (2013) que como consecuencia de una política errática que ha buscado compensar las injusticias del sistema de reparto, el volumen de recursos transferidos vía coparticipación ha ido perdiendo porcentaje con la aparición de otros recursos y fondos, alguno de ellos con asignación específica y otros de libre distribución con variada forma de reparto. Si bien estas correcciones resultan a todas luces necesarias habidas las críticas ya señaladas a la Ley $N^{\circ} 10.559$, el sistema ha adquirido una complejidad de difícil gobernabilidad.

26. Todo conflicto, en consecuencia, debería judicializarse.

27. Los impuestos descentralizables son el Impuesto Inmobiliario Rural, Impuesto a los Ingresos Brutos para el tramo de Pequeños Contribuyentes y el Impuesto a los Automotores - Embarcaciones Deportivas o de Recreación. En este caso, conf. los convenios, por administración tributaria del cobro de los mencionados impuestos hasta el $20 \%$ de lo recaudado en concepto de IIR, el 22,5\% de IIBB y el 50\% del Impuesto a las Embarcaciones Deportivas o de Recreación. Sin embargo, se ha dicho que este no es un caso de verdadera descentralización tributario sino una mera desconcentración de la función pues "la potestad sobre el impuesto (a quien y cuanto recaudar) la retiene el gobierno provincial. A su vez, los municipios bonaerenses transfieren lo recaudado al gobierno provincial, reteniendo para si solamente un porcentaje menor, en concepto de comisión por el servicio de recaudación" (Mangas, López Accotto y Martínez, 2016:158). 


\section{GRÁFICO I. TRANSFERENCIAS DE FONDOS ACUMULADAS A MUNICIPIOS - ACUMULADO A NOVIEMBRE DE 2019 TOTAL \$111.415.675.819}

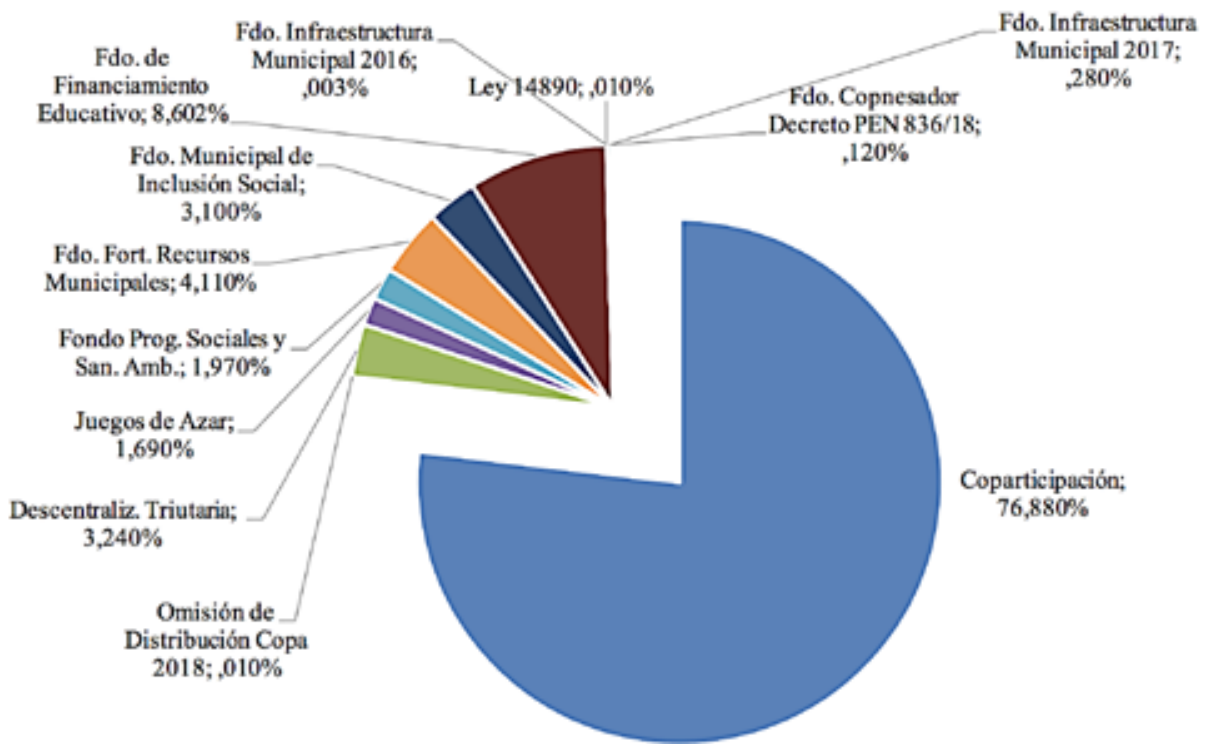

FUENTE: ELABORACIÓN PROPIA EN BASE A LA INFORMACIÓN DADA POR MINISTERIO DE ECONOMÍA DE LA PROVINCIA. HTTPS://WWW.GBA.GOB.AR/ECONOMIA/DIRECCION PROVINCIAL DE COORDINACION_MUNICIPAL_Y_PROGRAMAS DE_DESARROLLO/TRANSFERENCIAS_MUNICIPIOS. FECHA DE ACCESO: 12/01/20.

\section{GRÁFICO II. ORIGEN PORCENTUAL DE LOS FONDOS EN MUNICIPIOS SELECCIONADOS - AÑO 2017}

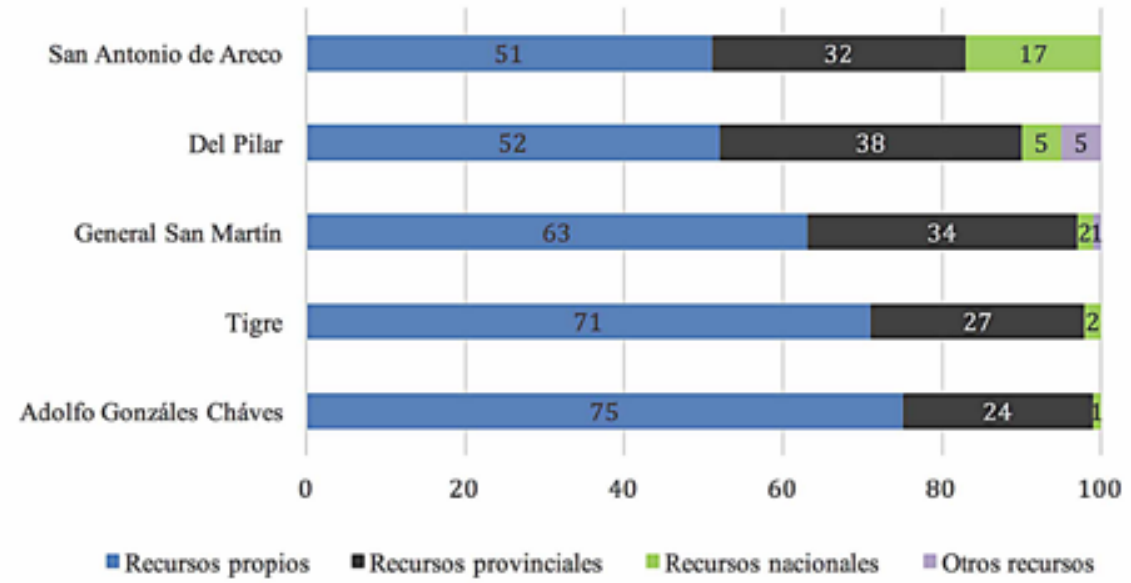

FUENTE: ELABORACIÓN PROPIA EN BASE A LOS DATOS DEL HONORABLE TRIBUNAL DE CUENTAS. HTTP://WWW.BUENOSAIRESABIERTA.ORG/ESTADISTICAS/ORIGEN-PORCENTUAL-DE-LOS-FONDOS. FECHA DE ACCESO: 12/09/19. 
Por su lado, los datos públicos que informa la Provincia solo proveen información porcentual sobre el origen de los fondos que reciben los municipios pero no distinguen si los mismos tienen o no afectación y en qué porcentaje. En el gráfico 2 se presenta la información existente sobre los municipios que hemos seleccionado para estudiar la incidencia de este tipo de fondos en la siguiente Sección. Como se advierte, el último dato actualizado que informa la Provincia, a través del Honorable Tribunal de Cuentas, pertenece a 2017.

Es por ello que entendemos necesario visibilizar este dato a través del análisis de los fondos percibidos por los municipios seleccionados estudiando el estado de ejecución presupuestaria informada en el sistema RAFAM.

\section{I I. LOS RECURSOSCONASIG N A IÓN ES P E CÍF I C A A L OS MUN I C I P IOS B O N A E R E NSES}

Mientras los fondos provinciales coparticipables son de libre disponibilidad, es decir, las autoridades municipales pueden dar el destino que mejor crean a través de sus ordenanzas presupuestarias, otro porcentaje de fondos se asignan con una afectación específica, esto es, son condicionados. Cuando ello sucede, el grado de decisión de los municipios es restringido y limita su capacidad y autonomía.

El primer diseño legal con este esquema es identificado por Catalano con la Ley $\mathrm{N}^{\circ} 13.010$ que “(...) además de la descentralización de responsabilidades de cobro de impuestos provinciales, [determinó la] fijación de destinos específicos de gasto para algunos recursos, con la creación de Fondos especiales" (Catalano, 2010:26). Sin embargo, el esquema vigente, es complejo y reconoce su primer antecedente en el año 1977 cuando el creado Sistema de Atención Médica Organizada (SAMO) mandaba que los fondos que les ingresaran a los municipios deban ser destinados a financiar gastos de funcionamiento e inversiones menores de capital ${ }^{28}$.

Con la Ley $\mathrm{N}^{\circ} 12.108^{29}$ de Promoción y fiscalización del deporte de 1988, los recursos del Fondo Provincial del Deporte que pudieren derivarse a organismos oficiales municipales se destinan a la asistencia del deporte en general (so-

28. Decreto-Ley N8801/77.http://www.gob.gba.gov.ar/legislacion/legislacion/79-1158.html http://www.gob.gba.gov.ar/legislacion/legislacion/79-1158.html

29. http://www.gob.gba.gov.ar/legislacion/legislacion/l-12108.html 
cial, escolar, federado), a la capacitación de científicos, técnicos y deportistas, a la construcción, ampliación y mantenimiento de instalaciones deportivas.

La Ley $\mathrm{N}^{\circ} 13.010$ genera un esquema más complejo de fondos y asignaciones. En el caso del Impuesto Inmobiliario Rural es administrado por los municipios de conformidad a los Convenios de Descentralización Administrativa Tributaria que se celebren, creando dos fondos específicos para Mantenimiento y Obras Vial y para Programas Sociales y Saneamiento Ambiental $^{30}$. En esa misma ley se crea un Fondo Provincial Compensador de Mantenimiento de Establecimientos Educativos alimentado con los impuestos sobre los Ingresos Brutos de contribuyentes que hayan tenido ingresos que no superen la suma de pesos novecientos mil (\$900.000). Aquellos municipios que suscriban los Convenios de Descentralización Administrativa Tributaria administrarán los fondos ingresados, aunque la distribución y asignación también se encuentra pautada según porcentajes preestablecidos. Este esquema continuó incrementándose con leyes posteriores. Así, la Ley $\mathrm{N}^{\circ} 13.163$, que crea el Fondo de Fortalecimiento de Programas Sociales y Saneamiento Ambiental, asigna los ingresos con destino a servicios de Asistencia Social y al tratamiento y disposición final de residuos ${ }^{31}$.

La Ley $\mathrm{N}^{\circ} 13.178$ que regula la venta de bebidas alcohólicas a destina el $50 \%$ la percepción del canon anual básico provenientes de las licencias a los Municipios para el financiamiento de las funciones de fiscalización y control así como a programas de educación, capacitación y prevención de las adicciones ${ }^{32}$.

También las asignaciones específicas le han venido impuestas por leyes na-

30. Para este caso, la distribución es: 65\% corresponderá a la Provincia; el $12 \%$ será destinado al Fondo Compensador de Mantenimiento y Obras Viales debiendo cada Municipio aportar al Fondo como mínimo el 12\% de la recaudación histórica determinada para cada ejercicio; el 3 \% será asignado al Fondo de Fortalecimiento de Programas Sociales y Saneamiento Ambiental, debiendo cada Municipio aportar al Fondo como mínimo el 3\% de la recaudación histórica determinada para cada ejercicio y el monto restante será asignado a los Municipios en concepto de retribución por la administración del tributo; ello conforme Ley $N^{\circ} 13.403$.

31. Artículo 6- (texto según Ley $N^{\circ}$ 13.403). "Los recursos del Fondo de Fortalecimiento de Programas Sociales y Saneamiento Ambiental serán distribuidos entre las Municipalidades de la Provincia de Buenos Aires según lo siguiente: a)El ochenta por ciento (80\%) con destino a la atención de los servicios de Asistencia Social, de acuerdo a un indice de vulnerabilidad social en cuya composición deberá contemplarse de manera relevante la cantidad de población bajo la línea de indigencia para cada caso, siendo esta distribución responsabilidad del Ministerio de Desarrollo Humano; b) El veinte por ciento (20\%) con destino al tratamiento y disposición final de residuos, en función de la población de cada distrito. Asimismo, los recursos correspondientes a los municipios cuya disposición final de residuos se efectúe según lo normado por el Decreto-Ley N 9111/78, conformarán una masa especial de fondos que se asignarán a los Municipios respectivos de acuerdo a lo que determine la reglamentación".

32. Un caso similar es el del Código de transito aprobado por Ley $N^{\circ} 13.927$ se crea una cuenta especial en el ámbito del Ministerio de Jefatura de Gabinete con el producido por cobro de tasas por servicios cuyos fondos deben destinarse para atender la infraestructura, equipamiento, gastos de funcionamiento y servicios, permitiéndoles a los Municipios que las Tasas por Servicios en su ámbito de competencia de conformidad puedan tener igual 
RIEM, No22, año XI, agosto-diciembre 2020, ISSN 0719-1790, pp. 63-91 cionales a las provincias y a los municipios. Así, el Decreto Nacional de Necesidad y Urgencia $N^{\circ} 206 / 09^{33}$ que creó el Fondo Federal Solidario, "con la finalidad de financiar, en Provincias y Municipios, obras que contribuyan a la mejora de la infraestructura sanitaria, educativa, hospitalaria, de vivienda o vial en ámbitos urbanos o rurales, con expresa prohibición de utilizar las sumas que lo compongan para el financiamiento de gastos corrientes". Por Ley $\mathrm{N}^{\circ} 13.976$ de la provincia se determinó que los municipios deberían adherir a la ley y asumir el compromiso de destinar los fondos exclusivamente, a las finalidades establecidas para que les sean transferidos los fondos.

Otro caso fue el de la Ley nacional $\mathrm{N}^{\circ} 26.075^{34}$, que propició el incremento de la inversión en educación, ciencia y tecnología, entre otros fines, a los de “h) Fortalecer la educación técnica y la formación profesional impulsando su modernización y vinculación con la producción y el trabajo. Incrementar la inversión en infraestructura y equipamiento de las escuelas y centros de formación profesional". La Ley local $N^{\circ}$ 15.078, determinó los montos y porcentajes a asignar y determinó que la Dirección General de Cultura y Educación pueda dictar las normas complementarias ${ }^{35}$.

Pero las afectaciones no surgen sólo de las leyes. También se ha introducido esta modalidad en convenios de transferencia de fondos desde la Administración Provincial a los municipios. Así, por Resolución N ${ }^{\circ}$ 110/10 del Ministerio de Desarrollo Social, en el marco de la regulación el Programa de Responsabilidad social Compartida Envión, se introduce una cláusula que determina la aplicación de los fondos trasferidos ${ }^{36}$. Algo similar sucede con el Decreto $N^{\circ} 898 / 16$ que aprueba el Convenio SAME Provincia con los

destino de afectación. Si bien no hay razones claras para el incremento en el uso de estos esquemas de repartos entre Provincia y municipios, puede advertirse una mayor presión de los intendentes, a través de los legisladores que los representan para negociar la aprobación de los paquetes impositivos. En efecto, un dato de la política local bonaerense de las últimas décadas es la territorialización de la Legislatura provincial y los pocos referentes propios que los gobernadores han tenido en el palacio legislativo. Este esquema de reparto de poder hace que los gobernadores deban negociar con intendentes las leyes claves, en especial, aquellas que generan nuevos fondos.

33. Esta norma fue derogada en 2018 Decreto, también de Necesidad y Urgencia, N 756/18 http://servicios.infoleg. gob.ar/infoleglnternet/anexos/310000-314999/313449/norma.htm. Sin embargo, como nuestro análisis contiene datos de 2017, también la hemos identificado.

34.http://servicios.infoleg.gob.ar/infoleglnternet/anexos/110000-114999/112976/norma.htm

35. Existen otros casos que si bien no cuadran en los parámetros hasta ahora descriptos tienen estructuras similares y que denotan una práctica que se ha consolidado. Por ejemplo, el Decreto nacional N 836/18 creó el Programa de Asistencia Financiera a provincias y municipios para asistir financieramente a las provincias que hayan aprobado el Consenso Fiscal del 16 de noviembre de 2017. En virtud de dicha norma el cincuenta por ciento (50\%) del monto que se les transfiera a las provincias se destinará a sus municipios, aplicando para su distribución el respectivo régimen de participación municipal de impuestos. Por Ley de presupuesto 2019, Ley №27.467 creó el Fondo de Compensación al transporte público de pasajeros por automotor urbano del interior del pais, fondo que si bien son remitidos a provincias y municipios, son girados luego a los beneficiarios a las empresa refinadora de hidrocarburos y empresas prestatarias del servicio público de pasajeros.

36. Véase cláusula quinta del Convenio. http://www.gob.gba.gov.ar/legislacion/legislacion/mds-10-110.html 
municipios ${ }^{37}$.

¿Cuánto representan estos fondos para los municipios? Para responder a estar pregunta hemos seleccionado cinco municipios de la Provincia de Buenos Aires: Adolfo Gonzales Chaves, Pilar, General San Martín, San Antonio de Areco y Tigre. Si bien la muestra es baja respecto de los 135 municipios que integran la organización política de la Provincia, como se verá es bastante representativa de las distintas realidades de sus municipios.

El primero de ellos, Adolfo Gonzales Chaves, fue creado en 1906. Emplazado en el sur de la provincia, este municipio tiene una población de poco más de 12 mil habitantes en el partido (INDEC, 2010), con un gran porcentaje de ella rural, en una superficie de total del partido de $3.859 \mathrm{~km}^{2}$. Sólo un 2,9\% de sus hogares tiene Necesidades Básicas Insatisfechas ${ }^{38}$. Pertenece políticamente a la sexta sección electoral de la Provincia ${ }^{39}$. Su producción es típicamente agrícola ganadera ${ }^{40}$. El Producto Bruto Geográfico (PBG), según los últimos datos desagregados publicados, representa el 0,16\% del Provincial $^{41}$.

El municipio de Pilar se encuentra al noroeste de la Provincia de Buenos Aires. Es uno de los municipios más antiguos de la Provincia aunque recién en el año 1912 es elegido el primer intendente. Cuenta con un total de 299.007 hab., la mayoría urbana ${ }^{42}$. Tiene 10.776 hogares con Necesidades Básicas Insatisfechas de un 82.671 total. Pertenece a la $1^{\text {a }}$ Sección Electoral, que aporta 15 diputados provinciales y 8 senadores provinciales. Su superficie es de $352 \mathrm{~km}^{2}$. Es uno de los municipios del Conurbano, aunque del tercer cordón. Junto con otros municipios colindantes, se caracterizan principalmente la presencia de grandes proyectos inmobiliarios y urbanizaciones, especialmente countries y los barrios semi-cerrados para las clases media-alta y alta. Cuenta con un gran parque industrial. Su PBG respecto del provincial es del 2,67\%, dos tercios de ellos correspondiente a bienes.

El municipio de San General Martín se asienta en el denominado primer cordón del Conurbano, lindante a la Ciudad Autónoma de Buenos Aires,

37. http://www.gob.gba.gov.ar/legislacion/legislacion/16-898.html

38. http://www2.mecon.gov.ar/hacienda/dinrep/Informes/archivos/NBIAmpliado.pdf

39. La 6a Sección Electoral de la Provincia de Buenos Aires aporta 11 diputados provinciales y 6 senadores provinciales.

40. Cuenta con un hospital municipal, Ilamado Anita Elicagaray.

41. A los efectos del cálculo del PBG tomaremos el informe con base año 2003, último publicado con este desagregado disponible en http://www.estadistica.ec.gba.gov.ar/dpe/images/pbgdesagrmuni.pdf

42. Sin embargo este número puede llegar a duplicarse los fines de semana y en época estival por la gran cantidad de casas de fin de semana en los barrios cerrados. 
lo cual le da una característica distinta a los restantes seleccionados. En efecto, con una población, según Censo 2010 de 431.854 hab. en sus 57,24 $\mathrm{km}^{2}$, es el distrito más densamente poblado del Conurbano después de los Partidos de Lanús, Vicente López y Tres de Febrero. Un 6,7\% de los hogares tienen Necesidades Básicas Insatisfechas. Está integrado en la primera sección electoral de la provincia que aporta 15 diputados provinciales y 8 senadores provinciales. Con tradicionales antecedentes industriales, alberga una de las universidades nacionales más pujantes de las creadas en la década de los 90. El PBG era, en 2003, el 4,52\% del total provincial.

El municipio de San Antonio de Areco, ubicado en el norte de la Provincia, pertenece a la $2^{\text {a }}$ Sección Electoral (que aporta 11 diputados provinciales y 5 senadores provinciales). Con una población 23.138 hab. según Censo 2010, la mayoría de ella urbana; 283 hogares con Necesidades Básicas Insatisfechas $(3,9 \%)$ y tiene una superficie de $857 \mathrm{~km}^{2}$. Es uno de los pueblos más tradicionales, declarado Capital Nacional de la Tradición, características que explota turísticamente, mayor fuente de sus ingresos. También se identifica como municipio cultural. Su PBG es del 0,22\% del total provincial.

Por último, seleccionamos el municipio de Tigre, otro de los municipios del Conurbano, ubicado en el norte del segundo cordón. Con un territorio de $368 \mathrm{~km} 2$, la mayor parte de ella insular y una población de 376.381 hab. según Censo 2010, la mayoría de ella urbana, se ha constituido en un municipio pionero en materia de seguridad y transparencia que hoy son tendencia para las políticas de gobernanza local. Ello ha posibilitado desde 2007 al líder del Frente Renovador sostener un bastión territorial como modelo de gestión. Integra la misma sección Electoral que Pilar. En cuanto a su faz sociodemográfica y productiva, Tigre tiene un $11,0 \% \%$ de sus hogares con NBI, aunque también grandes emprendimientos inmobiliarios y forma parte de uno de los destinos preferidos del turismo de cercanía. Aporta el $2,01 \%$ al PBG de la provincia.

Hemos seleccionado los recursos percibidos ${ }^{43}$ de los años 2017 y 2018 a través del estudio del presupuesto municipal para cada uno de los años en

\footnotetext{
43. Tomamos el criterio de lo percibido porque queremos analizar la cuenta del ejercicio clausurado, esto es, no el cálculo del recurso sino lo que efectivamente ingresó. Según la Ley Orgánica de las Municipalidades, el ejercicio financiero y patrimonial clausurado toma en cuenta dicho criterio. En efecto, el ejercicio clausurado el 31 de diciembre, podrá ser prorrogado, a los efectos del ajuste de la contabilidad, durante el mes de enero inmediatamente posterior y en el transcurso de este mes de prórroga se registrarán los ingresos percibidos y no contabilizados hasta el 31 de diciembre y podrán efectuarse pagos de compromisos preventivamente imputados al ejercicio vencido, siempre que se utilicen fondos correspondientes al mismo (conf. art. 173, Decreto-Ley 6.769/58). Conforme al Decreto $N^{\circ}$ 2.980/00, Reglamentario de la Ley Orgánica de las Municipalidades, en materia de recursos "La percepción o recaudación de los recursos se produce en el momento en que los fondos ingresan o se ponen a disposición de una oficina recaudadora, de un agente del Tesoro Municipal o de cualquier otro funcionario facultado para recibir los mismos."
} 
estos cinco municipios. Aclaramos que, para cada caso, están consideradas todas las fuentes de ingreso que tienen los municipios, esto es, recaudación propia, recursos transferidos por Nación y recursos transferidos por Provincia. Por los objetivos de este trabajo, en los cuadros y gráficos distinguimos los recursos de libre disponibilidad (cualquier fuere su origen), los afectados por la Provincia y los afectados por la Nación.

Si introducimos un análisis de los fondos con asignación específica por cantidad de $\mathrm{km} 2$ y habitantes para cada uno de los municipios estudiados

CUADRO I. - PRESUPUESTO - RECURSO PERCIBIDO 2017 - 2018 MUNICIPIO DE ADOLFO GONZALES CHAVES

\begin{tabular}{|l|c|c|c|c|}
\hline \multicolumn{1}{|c|}{ Recurso percibido } & $\mathbf{2 0 1 7}$ & PORCENTAJE & $\mathbf{2 0 1 8}$ & PORCENTAJE \\
$\begin{array}{l}\text { Recurso de libre } \\
\text { disponibilidad }\end{array}$ & $204.445 .534,51$ & 79,89 & $278.344 .544,47$ & 81,00 \\
\hline $\begin{array}{l}\text { Recurso afectado } \\
\text { Nación }\end{array}$ & 2.353 .314 & 0,92 & $753.958,39$ & 0,22 \\
\hline $\begin{array}{l}\text { Recurso afectado } \\
\text { Prov. Bs As. }\end{array}$ & $49.122 .339,39$ & 19,19 & $64.542 .337,00$ & 18,78 \\
\hline $\begin{array}{l}\text { TOTAL del Recurso } \\
\text { Municipal }\end{array}$ & $255.921 .187,90$ & 100 & $343.640 .839,86$ & 100 \\
\hline
\end{tabular}

FUENTE: ELABORACIÓN PROPIA EN BASE A LA EJECUCIÓN PRESUPUESTARIA.

\section{GRÁFICO III. - AÑO 2017}

Procentaje recurso percibido de libre disponbilidad, afectado por la nación y por provincia - Municipio de Adolfo Gonzales Chaves - 2017 19,194

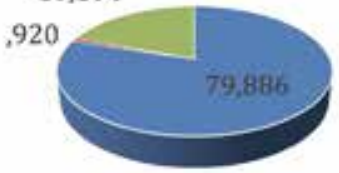

- Recurso de libre disponibilidad

- Recurso afectado Nación

- Recurso Afectado Prov. Bs As.

\section{GRÁFICO IV.- AÑO 2018}

Procentaje recurso percibido de libre disponbilidad, afectado por la nación y por provincia-Municipio de Adolfo Gonzales Chaves - 2018

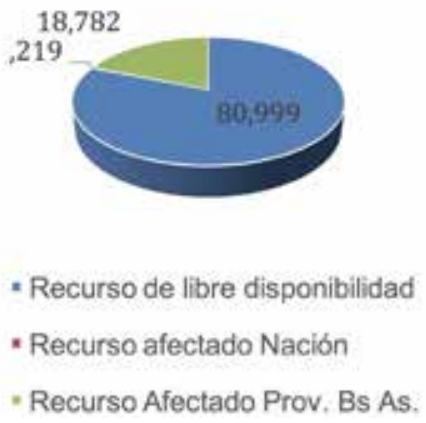


CUADRO II. - PRESUPUESTO - RECURSO PERCIBIDO 2017 2018 - MUNICIPIO DE PILAR

\begin{tabular}{|l|r|r|r|c|}
\hline \multicolumn{1}{|c|}{ Recurso percibido } & $\mathbf{2 0 1 7}$ & PORCENTAJE & $\mathbf{2 0 1 8}$ & PORCENTAJE \\
$\begin{array}{l}\text { Recurso de libre } \\
\text { disponibilidad }\end{array}$ & $3.384 .009 .698,39$ & 87,95 & $4.729 .931 .528,21$ & 88,66 \\
\hline $\begin{array}{l}\text { Recurso afectado } \\
\text { Nación }\end{array}$ & 97.464 .627 & 2,53 & 227.271 .158 & 4,26 \\
\hline $\begin{array}{l}\text { Recurso afectado } \\
\text { Prov. Bs As. }\end{array}$ & 366.053 .255 & 9,51 & 377.656 .151 & 7,08 \\
\hline $\begin{array}{l}\text { TOTAL del Recurso } \\
\text { Municipal }\end{array}$ & $3.847 .527 .580,36$ & 100 & $5.334 .858 .837,21$ & 100 \\
\hline
\end{tabular}

FUENTE: ELABORACIÓN PROPIA EN BASE A LA EJECUCIÓN PRESUPUESTARIA.

\section{GRÁFICO V. - AÑO 2017}

Procentaje recurso percibido de libre disponbilidad, afectado por la nación y por provincia - Municipio de Pilar - 2017

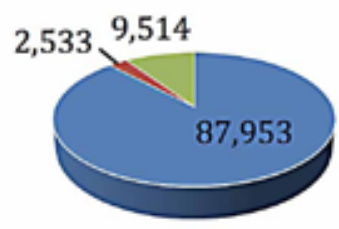

- Recurso de libre disponibilidad

- Recurso afectado Nación

- Recurso Afectado Prov. Bs As.
GRÁFICO VI. - AÑO 2018

Procentaje recurso percibido de libre disponbilidad, afectado por la nación y por provincia - Municipio de Pilar 2018

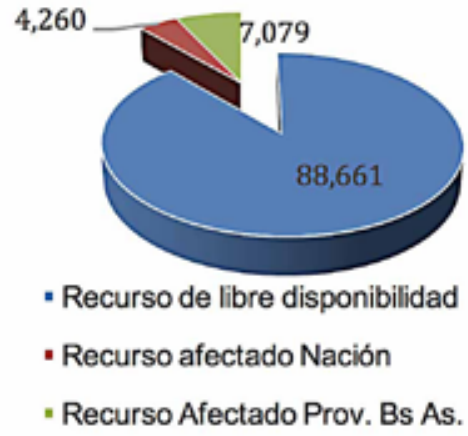


CUADRO III. -PRESUPUESTO - RECURSO PERCIBIDO 2017 2018 - MUNICIPALIDAD DE GENERAL SAN MARTÍN

\begin{tabular}{|l|c|c|c|c|}
\hline \multicolumn{1}{|c|}{ Recurso percibido } & $\mathbf{2 0 1 7}$ & PORCENTAJE & $\mathbf{2 0 1 8}$ & PORCENTAJE \\
\hline $\begin{array}{l}\text { Recurso de libre } \\
\text { disponibilidad }\end{array}$ & $4.974 .041 .974,25$ & 92,54 & $7.503 .264 .784,25$ & 92,58 \\
\hline $\begin{array}{l}\text { Recurso afectado } \\
\text { Nación }\end{array}$ & $61.420 .973,07$ & 1,14 & $126.655 .680,58$ & 1,56 \\
\hline $\begin{array}{l}\text { Recurso afectado } \\
\text { Prov. Bs As. }\end{array}$ & $339.625 .183,04$ & 6,32 & $474.736 .320,66$ & 5,86 \\
\hline $\begin{array}{l}\text { TOTAL del Recurso } \\
\text { Municipal }\end{array}$ & $5.375 .088 .130,36$ & 100 & $8.104 .656 .785,49$ & 100 \\
\hline
\end{tabular}

FUENTE: ELABORACIÓN PROPIA EN BASE A LA EJECUCIÓN PRESUPUESTARIA.

GRÁFICO VII. - AÑO 2017

Procentaje recurso percibido de libre disponbilidad, afectado por la nación y por provincia - Municipio de General San Martín - 2017

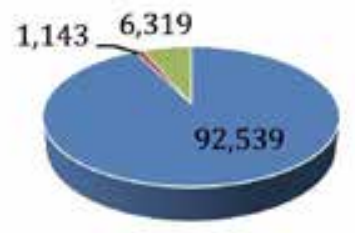

- Recurso de fibre disponibilidad

- Recurso afectado Nación

- Recurso Afectado Prov. Bs As.
GRÁFICO VIII. - AÑO 2018

Procentaje recurso percibido de libre disponbilidad, afectado por la nación y por provincia - Municipio de General San Martín - 2018

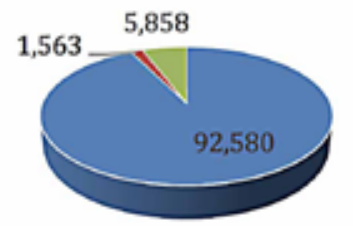

- Recurso de libre disponibilidad

- Recurso afectado Nación

- Recurso Afectado Prov. Bs As. 
CUADRO IV. - PRESUPUESTO - RECURSO PERCIBIDO 2017 2018 - MUNICIPALIDAD DE SAN ANTONIO DE ARECO

\begin{tabular}{|l|c|c|c|c|}
\hline Recurso percibido & $\mathbf{2 0 1 7}$ & PORCENTAJE & $\mathbf{2 0 1 8}$ & PORCENTAJE \\
\hline $\begin{array}{l}\text { Recurso de libre } \\
\text { disponibilidad }\end{array}$ & 439.940 .823 & 78 & $605.558 .180,03$ & 87,89 \\
\hline $\begin{array}{l}\text { Recurso afectado } \\
\text { Nación }\end{array}$ & $84.179 .352,04$ & 14,94 & $56.315 .098,31$ & 8,17 \\
\hline $\begin{array}{l}\text { Recurso afectado } \\
\text { Prov. Bs As. }\end{array}$ & $39.256 .880,67$ & 6,96 & 27.052 .259 & 3,92 \\
\hline $\begin{array}{l}\text { TOTAL del Recurso } \\
\text { Municipal }\end{array}$ & $563.377 .055,71$ & 100 & 688.925 .537 & 100 \\
\hline
\end{tabular}

FUENTE: ELABORACIÓN PROPIA EN BASE A LA EJECUCIÓN PRESUPUESTARIA.

GRÁFICO IX. - AÑO 2017

Procentaje recurso percibido de libre disponbilidad, afectado por la nación y por provincia - Municipio de San Antonio de Areco - 2017

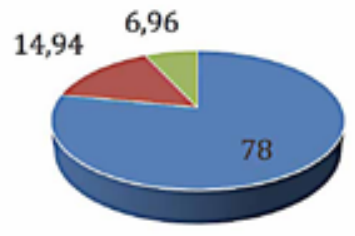

- Recurso de libre disponibilidad

- Recurso afectado Nación

- Recurso Afectado Prov. Bs As.
GRÁFICOX. -AÑO 2018

Procentaje recurso percibido de libre disponbilidad, afectado por la nación y por provincia - Municipio de San Antonio de Areco - 2018 $8,17 \quad 3,92$

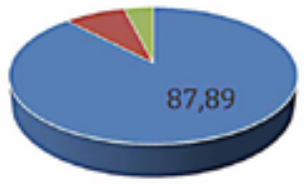

- Recurso de libre disponibilidad

- Recurso afectado Nación

- Recurso Afectado Prov. Bs As. 
CUADRO V. - PRESUPUESTO - RECURSO PERCIBIDO 2017 - 2018 TIGRE

\begin{tabular}{|l|c|c|c|c|}
\hline \multicolumn{1}{|c|}{ Recurso percibido } & $\mathbf{2 0 1 7}$ & PORCENTAJE & $\mathbf{2 0 1 8}$ & PORCENTAJE \\
\hline $\begin{array}{l}\text { Recurso de libre } \\
\text { disponibilidad }\end{array}$ & $4.478 .942 .583,32$ & 92,08 & $6.030 .719 .191,82$ & 94,19 \\
\hline $\begin{array}{l}\text { Recurso afectado } \\
\text { Nación }\end{array}$ & $95.479 .075,27$ & 1,96 & $29.716 .010,10$ & 0,46 \\
\hline $\begin{array}{l}\text { Recurso afectado } \\
\text { Prov. Bs As. }\end{array}$ & $290.021 .912,59$ & 5,96 & $341.947 .394,60$ & 5,34 \\
\hline $\begin{array}{l}\text { TOTAL del Recurso } \\
\text { Municipal }\end{array}$ & $4.864 .443 .571,18$ & 100 & $6.402 .382 .596,52$ & 100 \\
\hline
\end{tabular}

FUENTE: ELABORACIÓN PROPIA EN BASE A LA EJECUCIÓN PRESUPUESTARIA.

GRÁFICO XI. -AÑO 2017

Procentaje recurso percibido de libre disponbilidad, afectado por la nación y por provincia - Municipio Tigre 2017

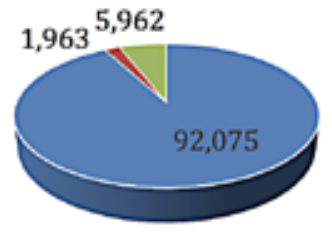

- Recurso de libre disponibilidad

- Recurso afectado Nación

- Recurso Afectado Prov. Bs As.
GRÁFICO XII. - AÑO 2018

Procentaje recurso percibido de libre disponbilidad, afectado por la nación y por provincia - Municipio Tigre 2018

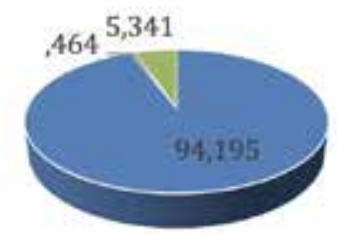

- Recurso de libre disponibilidad

- Recurso afectado Nación

- Recurso Afectado Prov. Bs As.

puede advertirse, al igual que en otros estudios que analizan la distribución de los fondos coparticipables ${ }^{44}$, la gran dispersión que existe en este tipo de fondos. En 2018, medido per cápita se asignan fondos por\$ 908,51 por habitante en Tigre hasta $\$ 5.357,53$ por habitante en Adolfo Gonzales 
Chaves; medido por km2, desde $\$ 16.725,11 / \mathrm{km} 2$ para Adolfo Gonzales Chaves hasta $\$ 8.293 .786,17 / \mathrm{km} 2$ para un municipio pequeño como General San Martín. La variabilidad de la distribución es producto, sin duda, consecuencia de la gran diversidad del tamaño, población y PBG.

CUADRO VI. - PRESUPUESTO CON ASIGNACIÓN ESPECÍFICA EN LOS MUNICIPIOS SELECCIONADOS POR KM2 Y PER CÁPITA AÑOS 2017 Y 2018.

\begin{tabular}{|c|c|c|c|c|}
\hline & \multicolumn{2}{|c|}{ km2 } & \multicolumn{2}{|c|}{ Habitantes } \\
\hline \multirow{2}{*}{$\begin{array}{l}\text { Municipio de Adolfo } \\
\text { Gonzales Chaves }\end{array}$} & \multicolumn{2}{|c|}{$3.859 \mathrm{~km}^{2}$} & \multicolumn{2}{|c|}{12.047 hab. } \\
\hline & $\begin{array}{r}2017 \\
\$ 12.729,29 / \mathrm{km}^{2}\end{array}$ & $\begin{array}{r}2018 \\
\$ 16.725,11 / \mathrm{km}^{2}\end{array}$ & $\begin{array}{r}2017 \\
\$ 4.077,55 / \text { hab }\end{array}$ & $\begin{array}{r}2018 \\
\$ 5.357,53 / \mathrm{hab} .\end{array}$ \\
\hline \multirow{2}{*}{ Municipio de Pilar } & \multicolumn{2}{|c|}{$352 \mathrm{~km}^{2}$} & \multicolumn{2}{|c|}{299.007 hab. } \\
\hline & $\begin{array}{r}2017 \\
\$ 1.039 .924,01 / \mathrm{km}^{2}\end{array}$ & $\begin{array}{r}2018 \\
\$ 1.072 .886,79 / \mathrm{km}^{2}\end{array}$ & $\begin{array}{r}2017 \\
\$ 1.224,22 / \mathrm{hab} .\end{array}$ & $\begin{array}{r}2018 \\
\$ 1.263,03 / \text { hab. }\end{array}$ \\
\hline \multirow{2}{*}{$\begin{array}{l}\text { Municipio de } \\
\text { General San Martín }\end{array}$} & \multicolumn{2}{|c|}{$57,24 \mathrm{~km}^{2}$} & \multicolumn{2}{|c|}{431.854 hab. } \\
\hline & $\begin{array}{r}2017 \\
\$ 5.933 .354,01 / \mathrm{km}^{2}\end{array}$ & $\begin{array}{r}2018 \\
\$ 8.293 .786,17 / \mathrm{km}^{2}\end{array}$ & $\begin{array}{r}2017 \\
786,43 / \text { hab. }\end{array}$ & $\begin{array}{r}2018 \\
1.099,29 / \mathrm{hab} .\end{array}$ \\
\hline \multirow{2}{*}{$\begin{array}{l}\text { Municipio de San } \\
\text { Antonio de Areco }\end{array}$} & \multicolumn{2}{|c|}{$857 \mathrm{~km}^{2}$} & \multicolumn{2}{|c|}{23.138 hab. } \\
\hline & $\begin{array}{r}2017 \\
\$ 45.807,32 / \mathrm{km}^{2}\end{array}$ & $\begin{array}{r}2018 \\
\$ 31.566,22 / \mathrm{km}^{2}\end{array}$ & $\begin{array}{r}2017 \\
\$ 1.696,64 / \text { hab. }\end{array}$ & $\begin{array}{r}2018 \\
\$ 1.169,17 / \text { hab. }\end{array}$ \\
\hline \multirow{2}{*}{ Municipio de Tigre } & \multicolumn{2}{|c|}{$368 \mathrm{~km}^{2}$} & \multicolumn{2}{|c|}{376.381 hab. } \\
\hline & $\begin{array}{r}2017 \\
\$ 788.103,02 / \mathrm{km}^{2}\end{array}$ & $\begin{array}{r}2018 \\
\$ 929.204,87 / \mathrm{km}^{2}\end{array}$ & $\begin{array}{r}2017 \\
\$ 770,55 / \text { hab. }\end{array}$ & $\begin{array}{r}2018 \\
\$ 908,51 / \mathrm{hab} .\end{array}$ \\
\hline
\end{tabular}

FUENTE: ELABORACIÓN PROPIA EN BASE A LA EJECUCIÓN PRESUPUESTARIA.

Finalmente, para analizar la racionalidad en la distribución del recurso hemos tomado los fondos que la Provincia asigna a los municipios específicamente a infraestructura escolar. Como hemos señalado más arriba estos recursos incluyen el Fondo Provincial Compensador de Mantenimiento de Establecimientos Educativos que se genera con los ingresos provenientes de impuesto sobre los Ingresos Brutos en el tramo correspondiente a contribuyentes que hayan tenido ingresos que no superen la suma de pesos novecientos mil (\$900.000), asignándose a este fondo el 25\% de la recaudación total del impuesto. En 2019 se modificó el articulado para que los fondos sean 
distribuidos entre los Consejos Escolares, en la proporción que la Dirección General de Cultura y Educación de la Provincia defina y para ser destinados al mantenimiento de los establecimientos escolares provinciales ubicados en su jurisdicción territorial Por otro lado, incluimos las transferencias de Nación a las provincias originadas en la Ley Nacional $N^{\circ} 26.075$ que determinó el compromiso del gobierno nacional, los provinciales y la Ciudad Autónoma de Buenos Aires de aumentar la inversión en educación, ciencia y tecnología. En Buenos Aires, a partir de la Ley $\mathrm{N}^{\circ}$ 15.078, Ley de presupuesto 2019, fondos asignados por la Nación a las Provincias, se asignaron a su vez por ésta en un porcentaje del 16,14\%, a los municipios. La norma prioriza los arreglos de I) las instalaciones de gas; II) las instalaciones eléctricas; III) las reparaciones de cubiertas; IV) las refacciones de sanitarios ${ }^{45}$.

Nuevamente y como se visualiza en el próximo cuadro, a pesar de algunos criterios objetivos para la distribución de estos fondos ${ }^{46}$, se advierte disper-

\section{CUADRO VII. - FONDOS PROVINCIALES ASIGNADOS A MUNICIPIOS AÑO 2018 PARA INFRAESTRUCTURA ESCOLAR}

\begin{tabular}{|l|c|c|c|}
\hline & $\begin{array}{l}\text { Total de fondos para } \\
\text { infraestructura escolar }\end{array}$ & $\begin{array}{l}\text { Cantidad de } \\
\text { establecimientos } \\
\text { escolares públicos }\end{array}$ & $\begin{array}{l}\text { Cantidad de matrícula en } \\
\text { establecimientos escolares } \\
\text { estatales }\end{array}$ \\
\hline $\begin{array}{l}\text { Municipio de Adolfo } \\
\text { Gonzales Chaves }\end{array}$ & $24.869 .557,21$ & 38 & 2.265 \\
\hline Municipio de Pilar & $174.121 .915,94$ & 137 & 55.860 \\
\hline $\begin{array}{l}\text { Municipio de } \\
\text { General San Martín }\end{array}$ & $145.841 .258,27$ & 164 & \\
\hline Municipio de San & $23.214 .370,87$ & 37 & 3.418 \\
Antonio de Areco & & & \\
\hline \\
Municipio de Tigre
\end{tabular}

FUENTE: ELABORACIÓN PROPIA EN BASE A LOS PRESUPUESTOS EJERCICIO 2018 Y DATOS DE LA DIRECCIÓN GENERAL DE CULTURA Y EDUCACIÓN DE LA PROVINCIA.

45 Esta priorización se da luego del accidente que sucediera en agosto de 2018 por una falla en una estufa alimentada por gas envasado en la escuela primaria №49 Nicolás Avellaneda de Moreno y que generó dos víctimas mortales (la vicedirectora y un auxiliar). 
siones cuando se calculan los fondos por establecimientos escolares y por cantidad de matrícula.

\section{GRÁFICO XIII. - FONDOS CON ASIGNACIÓN ESPECÍFICA EN INFRAESTRUCTURA ESCOLAR - AÑO 2018}

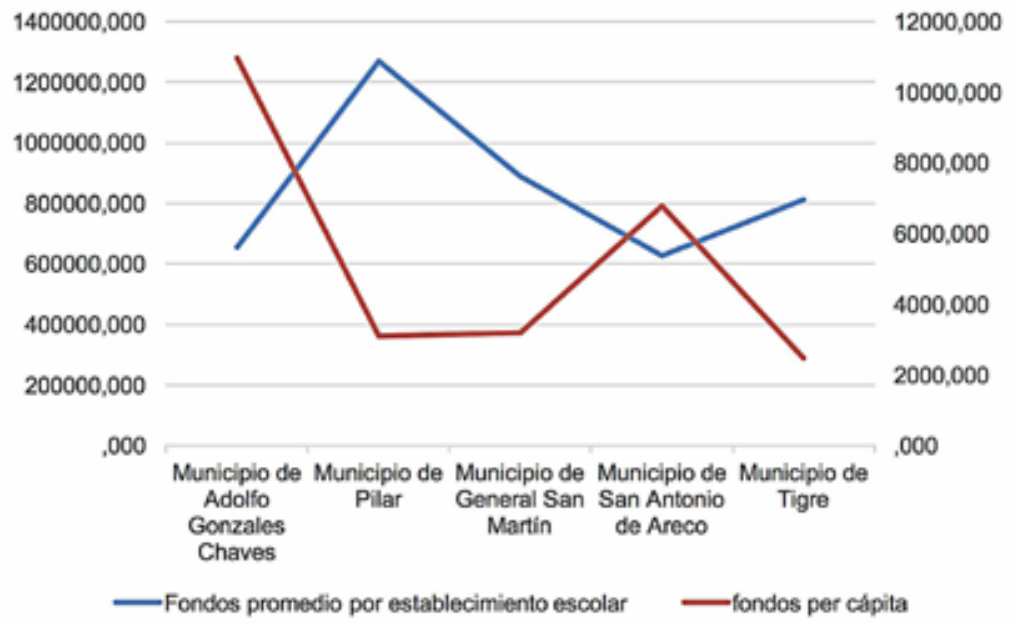

FUENTE: ELABORACIÓN PROPIA EN BASE A LA EJECUCIÓN PRESUPUESTARIA.

\section{V. C O N C L U S I O N E S}

Si bien las autonomías dadas a los municipios no son absolutas ${ }^{47}$ en 2014 el máximo Tribunal en "Intendente Municipal Capital s/Amparo" determinó que las provincias deben diseñar el modelo de autonomía municipal "con el mayor grado posible de atribuciones municipales en los ámbitos de actuación mencionados en el artículo 123" porque si se encontrasen sujetos en esos aspectos a las decisiones de una autoridad extraña -aunque se tratara de la provincial- ésta podría llegar a impedirles desarrollar su acción específica,

46. Recordemos que la Ley N 15.078 determina que la Dirección General de Cultura y Educación debe establecer un coeficiente, conformado por población, superficie y variables educativas relacionadas con matrículas, establecimientos, vulnerabilidad y resultados de las pruebas Aprender.

47. Este criterio ya ha sido reconocido en la interpretación del máximo Tribunal de nuestro país. En "Cadegua S.A. c/ Municipalidad de Junín" de 2004, el Procurador sostuvo que la reforma de 1994 no confiere a los municipios el poder de reglar las materias propias sin sujeción a límite alguno. En efecto, entendió que la autonomía constitucional de los municipios en los órdenes "institucional, político, administrativo, económico y financiero" que las provincias deben asegurar, está sujeta a la reglamentación que éstas realicen en cuanto a su "alcance y contenido", argumento que hizo suyo la Corte (Fallos, 327:4103). Puede verse el fallo en https://sjconsulta.csjn.gov.ar/sjconsulta/ documentos/verUnicoDocumentoLink.html?idAnalisis=567959\&cache $=1553796005270$ 
mediante diversas restricciones o imposiciones, capaces de desarticular las bases de su organización funcional.

Resulta evidente que la actual Constitución provincial de Buenos Aires limita la autonomía institucional, político y administrativa de sus municipios mermando las posibilidades del desarrollo de democracias locales que resistan los tradicionales procesos de centralización. Hemos indicado cómo diversas normas, pero particularmente su Ley Orgánica Municipal, restringen con detalladas reglamentaciones los alcances de sus intereses y servicios locales, funcionarios y cantidad de concejales, bases de actuación, procesos de compras, etc. Pero nuestra tesis central es que no son suficientes estas autonomías: ellas deben complementarse (en verdad estar todas presentes) junto con la autonomía económico financiera ${ }^{48}$.

Indicamos las distintas fuentes de ingresos que tienen los municipios. El solo hecho de que el mayor porcentaje de sus ingresos provengan de la Provincia (y no de fondos con origen en sus propias facultades tributarias) nos alerta acerca de la inviabilidad económica de los municipios bonaerenses. Que esta dependencia sea una nota del federalismo económico argentino (y que a su vez muchas de las provincias dependan para sus gastos corrientes de las transferencias de la Nación), no debe opacar este dato. Esta necesidad condiciona los posibles acuerdos interjurisdiccionales a una necesidad de supervivencia para los municipios en lugar de ser verdaderos esquemas de coordinación de políticas públicas ${ }^{49}$.

La existencia de una Ley de coparticipación automática y directa en la Provincia de Buenos Aires, la actual Ley $\mathrm{N}^{\circ} 10.559$, y que de ella se derive el mayor porcentaje de los fondos municipales, es un dato positivo en torno a la discusión de la autonomía en una futura reforma constitucional local. Sin embargo, dadas las críticas que tiene el sistema y la falta de actualización integral desde 1987 a la fecha, esta norma puede devenir inconstitucional y es necesaria su urgente reforma integral ${ }^{50}$. Dado que los elementos 
contextuales de los municipios bonaerenses son tan diversos, aun cuando estos fondos fijen variables de distribución en función de su población, $\mathrm{km} 2$, hospitales, capacidad tributaria y algunos de los servicios que prestan, la realidad es mucho más compleja que estas pocas variables por lo que, inevitablemente, se producen desvíos que tienden a la irracionalidad e ilegitimidad del sistema.

Ahora bien, mientras la discusión de validez de la ley provincial de coparticipación debe pasar por el matiz del análisis (y probanza) de la irracionalidad y gravedad institucional, en cambio, el reproche a la validez de la asignación específica de fondos de la provincia de Buenos Aires a sus municipios resulta más evidente.

En primer lugar, como hemos visto, la cantidad y porcentaje de fondos con asignación específica no es menor: representaron en 2017 hasta el 20\% en un municipio rural como Adolfo Gonzales Chaves mientras que, para el caso de San Antonio de Areco, fueron poco más de 5\% en el mismo año, porcentaje que se ve afectado por los altos ingresos que provinieron afectados por Nación en el marco del Decreto de Necesidad y Urgencia 206/09. Por su parte, en General San Martín, donde en términos absolutos representa un monto alto comparado con los otros municipios estudiados, su capacidad contributiva propia hace que ese monto no sea relevante para sus arcas (6,32\% y 5,86\% para 2017 y 2018 respectivamente). Esta variación resulta llamativa: aun cuando son fondos condicionados a la existencia previa de ciertas actividades o suscripción de convenios, esta disparidad pone en desigualdad a los municipios, ya muy desiguales en tamaño, población y capacidad contributiva.

Cuando detallamos los fondos asignados a los municipios para infraestructura escolar año 2018, detectamos cómo se afecta además del principio de igualdad, el de racionalidad: en promedio, cada uno de los ciento treinta y siete establecimientos escolares de Pilar recibiría \$ 1.270.962,89 mientras que en San Antonio de Areco sólo \$ 627.415,43; medidos por alumnos, hay un ingreso para infraestructura escolar por alumno de \$10.979,94 en Adolfo

50. En efecto, en un fallo contra la Provincia de Santiago del Estero impulsado por el Municipio de La Banda, el hecho de que el organismo encargado de hacer efectiva la distribución de fondos entre los municipios continúe, luego de veinte años, incumpliendo su obligación de actualizar los índices pone en entredicho de manera irrazonable y arbitraria el esquema ideado por el constituyente y el legislador provincial y una grave afectación en su autonomía, lo que encierra una evidente gravedad institucional. El fallo podría ser aplicable análogamente a la Provincia de Buenos Aires por mantener y no actualizar los porcentajes de coparticipación. Ver fallo en https://sjconsulta.csjn. gov.ar/sjconsulta/documentos/verDocumentoByldLinksJSP.html?idDocumento $=7466342$ \&cache $=1537488021000$ 
Gonzales Chaves mientras que en Tigre es de solo \$2.474,11. La asignación de estos recursos a las escuelas resulta de particular importancia social, por ser instrumento, medio y vehículo para el progreso de una comunidad y porque la escolaridad es uno de los indicadores para medir las NBI y el desarrollo económico de un país.

La heterodeterminación en el gasto de los recursos no sólo afecta principios de ejecución presupuestaria, reconocidos en las leyes de administración financiera de la Nación y provincia, sino que limita la ya débil capacidad de decisión de las autoridades locales. En verdad, la decisión de otra jurisdicción sobre qué y cuánto gastar, que opera como una mera descentralización del gasto, termina condicionando jurídica y políticamente a quien gasta/ ejecuta; lo hace jurídica y políticamente responsable ante órganos del propio ente que descentraliza el gasto ${ }^{51}$.

Como hemos señalado, el complejo entramado de leyes y resoluciones que existe en la provincia de Buenos Aires le asigna a sus municipios fondos para atención médica, capacitación de científicos, para el tratamiento y disposición final de residuos, para la atención de servicios de asistencia social, entre otros. Estas son funciones ciertamente locales pero también provinciales, en concurrencia. No significa esto que pretendamos que esos fondos sean absorbidos, modificación legislativa mediante, por la Provincia sino todo lo contrario: cada uno de los actores del federalismo argentino debe tener capacidad y recursos efectivos para realizar su función y cada uno, asumir las responsabilidades políticas inherentes a la decisión de cómo invertir esos recursos.

Resulta claro también que cuando un fondo es afectado a un destino específico para que otra institución lo ejecute, aquél quien definió a qué destino y con qué porcentaje, ese es quien verdaderamente gobierna. De allí que aunque la constitución provincial se adecúe a los preceptos de la constitución nacional -o algún intendente quiera hacer valer judicialmente su autonomía- estas normas van a condicionar económicamente a un municipio política, administrativa e institucionalmente "autónomo".

Entendemos que estas restricciones jurídicas, políticas y económicas limitan el desarrollo local: el municipio es la mejor escala para el conocimiento directo de las necesidades; para promover la participación y la que genera mayor derrame sobre los proveedores y actores de la ciudad. La intrínse-

51. Con respecto a los criterios de eficiencia y equidad, Piffano (2012) propone descentralizar lo máximo posible el gasto público y el financiamiento tributario, minimizando asi la brecha fiscal y la necesidad de transferencias verticales (nación-provincias; provincia-municipios). 
ca heterogeneidad de los municipios bonaerenses hace que toda decisión general impuesta desde la gobernación provincial tienda a introducir desvíos, injusticias y gastos innecesarios.

Creemos que la eficiencia de escala, la posibilidad real de participación y control social, la información directa sobre las necesidades y el mejor "derrame" sobre los actores productivos locales son criterios válidos y sólidos para reconsiderar la utilidad de este tipo fondos.

La provincia de Buenos Aires mantiene una deuda, no solo económica, sino jurídico-política con sus propios municipios y ciudadanos para que el impacto de decisiones exógenas no afecten las ya sobrecargadas espaldas de las políticas locales. 


\section{R E F E R E N C I A S}

ÁBALOS, M. (2017). Cuentas pendientes de la autonomía municipal en la Argentina. Revista La Ley. (2017-A). (p 881).

AGOSTO, W. (2017). La relación fiscal entre el gobierno nacional y las provincias: la película. Documento de políticas públicas. CIPPEC. Recuperada 08/01/2020, de https:// www.cippec.org/wp-content/uploads/2017/11/194-DPP-ADE-La-relaci\%C3\%B3n-fiscal-entre-el-gobierno-nacional-y-las-provincias-la-pel\%C3\%ADcula-Walter-Agosto-noviembre-2017.pdf

ÁLVAREZ ECHAGÜE, J. (2005). “La potestad tributaria a partir del concepto constitucional de autonomía. Periódico Económico Tributario. (abril- 322). Recuperada 10/01/2020, de http://www.saij.gob.ar/doctrina/dacf050057-alvarez_echague-potestad_tributaria_partir_concepto.htm\#

ARGENTINA (2014). Dirección Nacional de Coordinación Fiscal con las Provincias (2014). Regímenes de Coparticipación a Municipios. Documento elaborado por la Mesa de Responsables de Asuntos Municipales de la República Argentina. Año 2013. Recuperada 2701/2020, de http://equiposweb.com.ar/web/wp-content/uploads/Regimenes-de-coparticipacion-a-municipios-version-final-1.docx

BAISTROCCHI, E. (1996). La autonomía de los municipios de provincia: sus posibles consecuencias tributarias. Revista La Ley (D), (p.p.1173 - 1197).

BENNARDIS, A. (1999). "Gestión Municipal en el Conurbano Bonaerense”, en Blutman, Gustavo (compilador) Investigaciones sobre Reforma del Estado, Municipio y Universidad. Serie Investigación en Administración Pública, Facultad de Ciencias Económicas, Universidad de Buenos Aires.

CATALANO, C. (2010). La potestad tributaria municipal en la provincia de Buenos Aires. Experiencia de la descentralización de la administración tributaria realizada por ley $\mathrm{N}^{\circ}$ 13.010. Tesis de maestría en Finanzas públicas. Disponible en http://sedici. unlp.edu.ar/handle/10915/31734.

FLORES, H; GIL, M; IPARRAGUIRRE, E., y ALTAVILLA, C. (2016). Las decisiones del gasto público y el rol de los municipios en el desarrollo local en Argentina. Un abordaje desde la autonomía municipal y los actores sociales y políticos (2004-2006). Revista Terra. N. (IV). (p.p. 1 a 31).

GARCÍA BELSUNCE, H. (1982). Impuestos y tasas municipales. Temas de derecho tributario. Buenos Aires: Abeledo Perrot.

GOLA, L., y SCHIAVI M. (2017). La coparticipación provincial bonaerense. SERIE DOCUMENTOS CEM Nº6- AGOSTO 2017. Recuperada 10/01/2020, de http://estudiosmetropolitanos.com.ar/wp-content/uploads/2017/08/La-coparticipaci\%C3\%B3n-provincial-bonaerense.pdf 
GUTIÉRREZ, R., y ALONSO G. (2018). Gobierno municipal y coordinación interjurisdiccional de políticas públicas. Revista Documentos y Aportes en Administración Pública y Gestión Estatal. (31). (pp. 57-80).

LÓPEZ ACCOTTO, A; GRINBERG, I., y MARTÍNEZ, C. (2010). Estudio de las transferencias monetarias de la Provincia de Buenos Aires hacia sus municipios: tendencias y alternativas. Documentos y Aportes en Administración Pública y Gestión Estatal. $\mathrm{N}^{\circ}$ (XIV). (p.p. 73-111). Recuperada 13/04/2020, de https://bibliotecavirtual.unl.edu.ar/ publicaciones/index.php/DocumentosyAportes/article/view/1254/1959

LÓPEZ ACCOTTO, A., MARTÍNEZ, C., GRINBERG I., y MANGAS, M. (2013). La provincia de Buenos Aires y sus municipios: los laberintos de una distribución anacrónica de recursos. Los Polvorines: Universidad Nacional de General Sarmiento.

LOSA, N., y COHN, S. (1998). Atribuciones municipales y deberes de los ciudadanos. Buenos Aires: Abeledo- Perrot.

MANGAS, M., LÓPEZ ACCOTTO, A., y MARTÍNEZ, C. (2016). La situación fiscal de las ciudades argentinas. RIEM. $\mathrm{N}^{\circ}$ (XIV). (Año VII). (pp. 151-184). Recuperada 13/04/2020, de https://revistariem.cl/index.php/riem/article/view/95

MARTÍNEZ, C., (2018). El rol del gobierno provincial en el financiamiento de los municipios (2013-2018). PARA EL CONURBANO, NO ALCANZA. Informe del Observatorio del Conurbano Bonaerense. Universidad Nacional de General Sarmiento. Recuperada 16/01/2020, de http://observatorioconurbano.ungs.edu.ar/wp-content/uploads/ El-rol-del-gobierno-provincial-en-el-financiamiento-de-los-municipios-2013-2018.pdf.

MUÑOZ, P. (2019). Las causas de la alta litigiosidad en materia de tasas municipales: un estudio sobre la jurisprudencia de dos tribunales supremos. Tesis de maestría en Derecho y Economía. Universidad Torcuatro Di Tella.

NAVA ESCUDERO, O. (2014). Derecho Presupuestario Mexicano. México: Porrúa.

OBSERVATORIO DEL ESTADO PROVINCIAL (2018). Transferencias de Nación a municipios de la Provincia de Buenos Aires. Impacto en la distribución. Instituto Patria. Recuperada 20/01/2020, de http://equiposweb.com.ar/web/wp-content/uploads/ TRANSFERENCIAS-DE-NACION-A-MUNICIPIOS-PBA-25-7.pdf

PIFFANO, H. (2012). Análisis económico del derecho tributario. La Plata: EDULP. 
